\title{
Multiple background corrections for U-Th disequilibrium dating of zircon - visualisation and reduction via Crayfish
}

\author{
RUBY C. MARSDEN ${ }^{1}$, CHRIS L. KIRKLAND ${ }^{1}$, MARTIN
} DANIŠÍK $^{2}$, NOREEN J. EVANS ${ }^{1,2}$, MATTHEW DAGGITT ${ }^{1}$

${ }^{1}$ School of Earth and Planetary Sciences, Curtin University, Perth, WA 6102, Australia

(*correspondence: ruby.marsden@postgrad.curtin.edu.au)

${ }^{2}$ John de Laeter Centre, Curtin University, Perth, WA 6102, Australia

U-Th disequilibrium dating of zircon by Secondary Ionization Mass Spectrometry (SIMS) has been utilized to date crystallization ages $<350 \mathrm{ka}$, with wide application in Quaternary geochronology. When conducted on SIMS instruments, U-Th disequilibrium dating is complicated by the presence of a background peak on the lower mass side of the ${ }^{246} \mathrm{ThO}$ peak. The magnitude of this background signal varies and its high mass tail can mask the ${ }^{246} \mathrm{ThO}$ signal, leading to erroneous results.

In this contribution, we present a new computer program written in Python that can import the standard output file of the SHRIMP II instrument and correctly parse the relevant mass stations. The program effectively models the high-mass decline of the background peak as an exponential decay function from two background measurements, and finally, calculates a U-Th disequilibrium age for each analysis. Visualisation of the background correction process for each spot analysed can be provided to verify it efficacy.

Using this program, a case study dataset from a sample of zircon crystals with known age of $31 \pm 8$ ka results in an age of $52 \pm 6$ ka using the standard constant background correction. An improved age of $41 \pm 5 \mathrm{ka}$ is obtained with the program when an exponential background correction is applied. This program improves the accuracy of young age determination and extends the capability of SQUID (Ludwig, 2009) by considering multiple background measurements to generate a single background model used in correction.

Ludwig, K.R., 2009. SQUID 2: Berkeley Geochronology Center Special Publication, 5, p.110. 